Injury, Int. J. Care Injured xxx (2016) xxx-xxx

Review

\title{
Influence of implant properties and local delivery systems on the outcome in operative fracture care
}

\author{
W-J. Metsemakers ${ }^{\mathrm{a}, \mathrm{b}, *}$, T.F. Moriarty ${ }^{\mathrm{a}}$, S. Nijs ${ }^{\mathrm{b}}$, H.C. Pape ${ }^{\mathrm{c}}$, R.G. Richards ${ }^{\mathrm{a}}$ \\ ${ }^{a}$ AO Research Institute Davos, Switzerland \\ ${ }^{\mathrm{b}}$ University Hospitals Leuven, Department of Trauma Surgery, Leuven, Belgium \\ ${ }^{\mathrm{c}}$ University of Aachen Medical Center, Department of Orthopaedic Trauma, Aachen, Germany
}

\section{A R T I C L E I N F O}

\section{Article history:}

Accepted 15 January 2016

\section{Keywords:}

Complications

Nonunion

Compromised fracture healing

Implant-related infection

Titanium

Stainless steel

Gentamicin

Coating

\begin{abstract}
A B S T R A C T
Fracture fixation devices are implanted into a growing number of patients each year. This may be attributed to an increase in the popularity of operative fracture care and the development of ever more sophisticated implants, which may be used in even the most difficult clinical cases. Furthermore, as the general population ages, fragility fractures become more frequent. With the increase in number of surgical interventions, the absolute number of complications of these surgical treatments will inevitably rise. Implant-related infection and compromised fracture healing remain the most challenging and prevalent complications in operative fracture care. Any strategy that can help to reduce these complications will not only lead to a faster and more complete resumption of activities, but will also help to reduce the socio-economic impact. In this review we describe the influence of implant design and material choice on complication rates in trauma patients. Furthermore, we discuss the importance of local delivery systems, such as implant coatings and bone cement, and how these systems may have an impact on the prevalence, prevention and treatment outcome of these complications.
\end{abstract}

(c) 2016 Elsevier Ltd. All rights reserved.

\section{Contents}

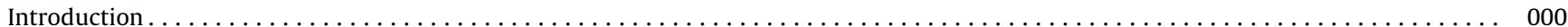

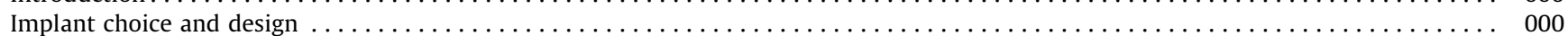

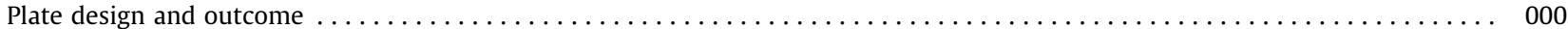

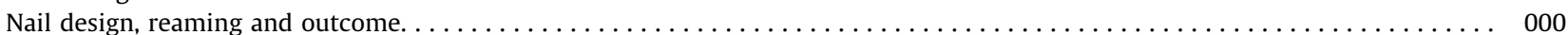

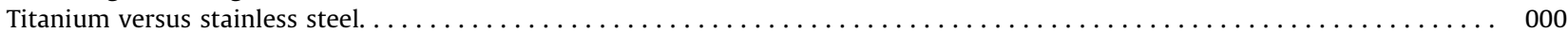

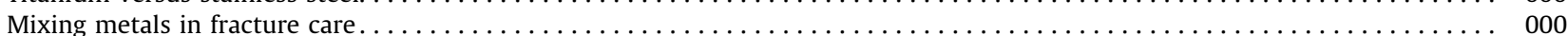

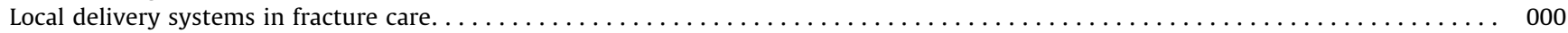

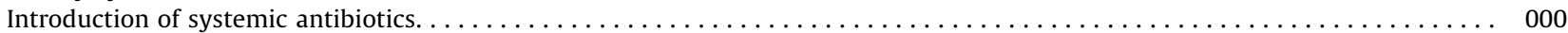

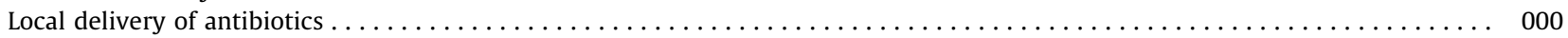

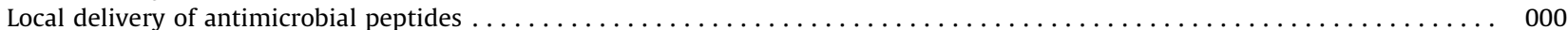

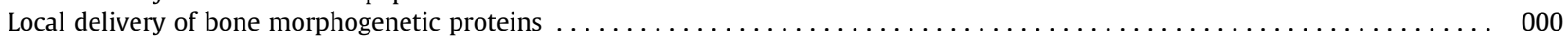

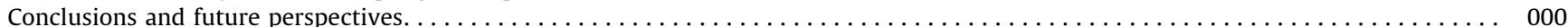

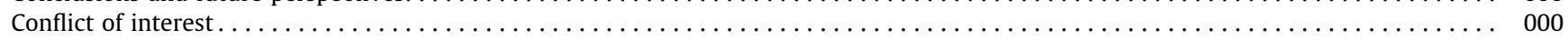

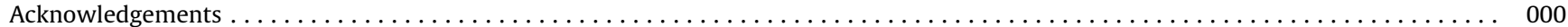

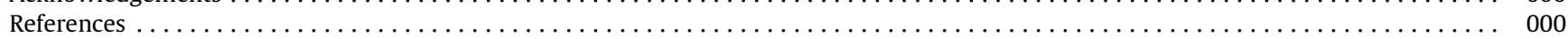

* Corresponding author at: Department of Trauma Surgery, University Hospitals Leuven, Herestraat 49, 3000 Leuven, Belgium.

E-mail address: wilhelmus.metsemakers@uzleuven.be (W.-J. Metsemakers). 


\section{Introduction}

The most challenging musculoskeletal complications in trauma surgery are implant-related infection and compromised fracture healing [1-5]. These complications may result in permanent functional loss or even amputation in otherwise healthy patients [6]. Furthermore, the reported socio-economic effect is significant. Darouiche published that in cases of implant-related infection, the costs per patient could be as high as 15,000 USD [3]. Hak et al. stated that the direct treatment cost of an established nonunion was 11,000 USD [5]. In a study by Chung et al., amputation was compared to limb salvage in grade IIIb and IIIc open tibia fractures. The reported lifetime cost, in complicated cases that underwent amputation, could be up to 680,000 USD [7].

Accurately estimating the impact of fracture related complications has been hampered by the lack of clear definitions for these complications: for example, there is a lack of consensus regarding the definition of compromised fracture healing, for which there are no available standard criteria [1]. 'Compromised fracture healing' and 'nonunion' are general terms for healing disturbances, and are used interchangeably in this text.

In this review, we describe the latest research aimed at understanding the factors that may lead to implant-related infection, fracture healing complications, and the development of strategies to prevent and treat them. In particular, we describe the contribution of implant properties and local delivery systems on complications in fracture care. Data will be drawn from preclinical experimental research as well as translational and clinical studies to illustrate the current research directions in this field.

\section{Implant choice and design}

\section{Plate design and outcome}

The influence of the implant on the outcome in fracture care has been described in different publications over the past decades [8-12]. Over time, different plate concepts or designs have been created, from the dynamic compression plate (DCP), the limited contact DCP (LC-DCP) (Fig. 1), through to point contact fixator (PCFix) and more recently the locking compression plate (LCP) [8]. These devices have been developed to improve fracture healing, reduce soft tissue and vascular damage but it also has been found that these devices have a different susceptibility to infection $[8,13]$. Experimental studies demonstrated that implant designs that reduce the area of necrosis in and near the area of contact with the bone have reduced infection rates [14]. This is believed to be due to the fact that infection spreads along a contiguous area of

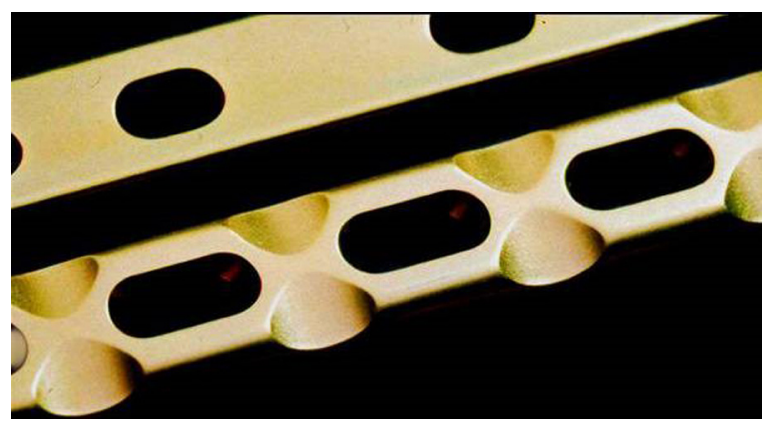

Fig. 1. Dynamic compression plate (DCP; top) and limited contact dynamic compression plate (LC-DCP; bottom). In the LC-DCP design the area of platebone contact (footprint) is greatly reduced thus improving cortical perfusion. Images reproduced with kind permission of the Copyright by AO Foundation, Switzerland [12]. necrosis [14]. The goal of biological internal fixation is to minimise and isolate bone-implant contact, whilst at the same time allow adherence or integration with adjacent tissue to avoid a fluid-filled dead space.

The DCP provides fixation by compression of bone fragments across the fracture gap and also compression between the plate and the underlying bone across a large footprint [6]. The large area of compression results in compression induced restriction of blood flow to the periosteum and in the bone, leading to tissue necrosis [8]. The more recently developed, so-called locked internal fixators (e.g. PC-Fix and Less Invasive Stabilization System (LISS)), consist of plate and screw systems where the screws are locked in the plate, which reduces the area of contact between the plate and bone minimising, the damage caused to the periosteum (Fig. 2) [8,15].

The greater protection of the periosteum provided by the PCFix, leading to greater viability of tissues, improved fracture healing by reducing tissue necrosis, but also improved resistance to infection in comparison with DCP implants by the same mechanism [8]. Eijer et al. investigated, in a rabbit model, local infection rates after fracture fixation with plate osteosynthesis, performed by different implantation techniques [14]. The overall infection rate was higher for the DCP-group with surface contact compared with the PC-Fix group with point contact. The development of the LCP has only been possible based on the experience gained with the PC-Fix $[8,12,15]$. The LCP with combination holes can be applied, using a conventional technique (compression principle), a bridging technique (internal fixator principle), or a combination technique (compression and bridging principles), depending on the fracture type [12,15].

\section{Nail design, reaming and outcome}

IMN was already introduced by Küntscher in 1939 [16]. It is the treatment of choice for shaft fractures of long bones. With respect

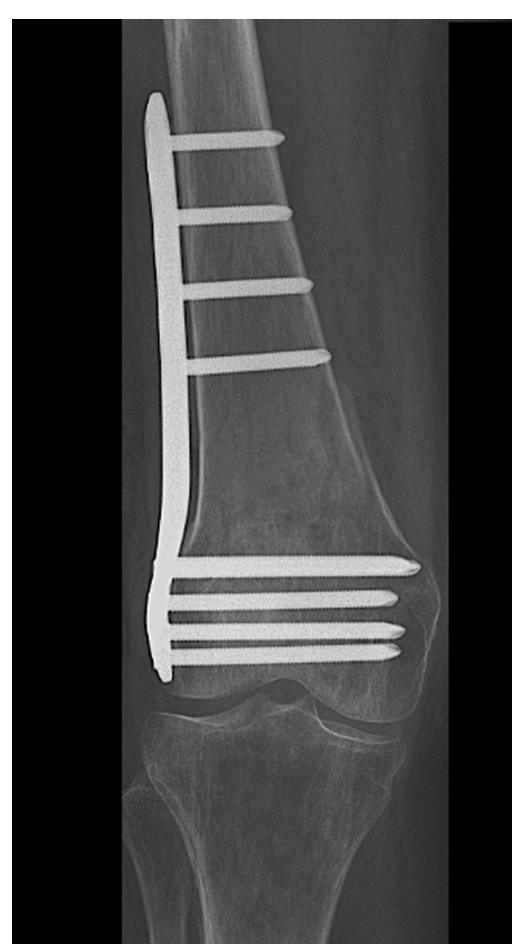

Fig. 2. The concept of the Less Invasive Stabilization System (LISS) comprises a contoured plate to which the screws interlock. Stability comes from the angular stability of the plate-screw interface and not from friction between plate and bone. By this method the system minimises implant-to-bone contact and consequently avoid vascular damage to the osseous blood supply. 
to nail design, experimental preclinical models show that infection is more likely to occur after IMN with hollow nails than with solidcore nails. In a study by Horn et al., for example, the aim was to determine if cannulated intramedullary nails had a lower resistance to infection than solid nails. In rabbits, the intramedullary cavity was inoculated with Staphylococcus aureus, and one of the nails was inserted. The solid nail had a greater resistance to infection compared to that of the cannulated nail [9]. Melcher et al. published analogous results in two similar animal studies $[17,18]$. An explanation for these results may be the fact that there is less 'dead-space' in solid-core nails compared with cannulated nails, whereby the dead space allows biofilm formation in the absence of vascularisation and associated host defences. In a clinical study in human patients, Riemer et al. treated 29 patients with tibial diaphyseal fractures with unreamed solid core nails for nonunion after initial long-term stabilisation with external fixators [19]. Infection rates were low, although the authors reported already a few local infections before placement of the nails. This is remarkable, as we know that late conversion of external fixation to IMN increases the risk of infection as does the appearance of active pin tract infections [20].

Although it is clear that nail design has an impact on the outcome, the factor of reaming needs to be taken in to account as well, especially because of the correlation between nail design and the necessity to ream the fracture site (e.g. reamed (hollow) and unreamed (solid) nails). Intramedullary reaming allows shaping of the medullary canal facilitating the insertion of larger diameter nails, which provides a more stable osteosynthesis [21]. A described advantage of reaming would be that the debris is a source of mesenchymal stem cells (MSC's) and growth factors that contribute to accelerated bone healing [22]. The MSC's are derived from bone marrow and trabecular bone fragments [22]. Although this seems positive, not all long bones are suitable for reaming. Most studies advise for example the use of unreamed nails in the humerus, as reaming can cause iatrogenic fractures and uncontrolled fragment movement putting the adjacent radial nerve at risk [23]. Other side effects associated with intramedullary reaming are partial destruction of the medullary blood supply [24], as well as generation of high pressure and an increase in temperature within the medullary cavity $[25,26]$. With respect to femoral shaft fractures, concerns have risen regarding the local and systemic effects of reaming. The procedure leads to elevated intramedullary pressure and systemic embolisation of bone marrow contents [21]. Consequently intramedullary instrumentation results in stimulation of the inflammatory system [27]. These systemic disturbances could contribute to pulmonary morbidity, due to acute respiratory distress syndrome (ARDS), in patients with multiple injuries [28]. A study performed by the Canadian Orthopaedic Trauma Society however, found that there was no difference in the incidence of ARDS between patients receiving reamed and unreamed IMN [29].

Regarding compromised fracture healing, the influence of reaming on the outcome of long bone fracture treatment is still a subject of debate [30]. Comparative studies between reamed and unreamed nailing in femoral shaft fractures give conflicting results on healing outcome [31-35]. A recent large prospective trial gave more insight on treatment outcomes of tibial shaft fractures [36]. The authors stated that reaming resulted in a better outcome in closed fractures compared to open fractures. More specifically, open fractures as a whole were associated with statistically equivalent reoperation rates, but there was a trend toward better healing in those receiving unreamed IMN. This was confirmed by Metsemakers et al. in a recently published large retrospective study [37].

The correlation between reaming and infection has also been an issue of debate over the past decades. In an experimental study by
Melcher et al. the same solid steel nail was inserted either with prior reaming of the medullary cavity or without reaming in rabbit tibia [17]. All rabbit tibia were inoculated with S. aureus. Lower infection rates were observed in the unreamed group versus the reamed group, although the difference was small (50\% versus $64 \%$ infection rate). An explanation for these results is that in complex open fracture cases with extensive periosteal stripping, the external blood supply through the periosteum has been compromised. The bone now depends on its medullary supply, which will be destroyed by the reaming procedure. Indeed Schemitsch et al. showed, in a sheep model, that reaming essentially interrupts cortical perfusion. This was reversible within $8-12$ weeks, however the limited blood supply prevents antibiotics from reaching the fracture site and, in combination with a higher bacterial load in open fractures, could theoretically also lead to higher infection rates [38].

Clearly, there remain many questions regarding the impact of implant choice and reaming on the outcome in fracture care today. Further experimental and clinical studies are required to provide an understanding of the fundamentals of these issues.

\section{Titanium versus stainless steel}

Uncoated metal implants, usually stainless steel, titanium or titanium alloys (titanium-6\% aluminium-7\% niobium (TAN)) are the most commonly used materials used in fracture care today [39]. All these materials offer acceptable mechanical properties and biocompatibility, however there are certain differences. Titanium and its alloys have a lower modulus of elasticity compared to other metals like stainless steel. Consequently, this allows for increased flexibility, which means that the elastic deformations on titanium implants are a closer reflection to that of bone [40].

Besides elasticity, the surface oxides of both materials are different [39]. They differ in chemistry, thickness and their ability to regenerate, which affects metal ion release from the surface. Titanium and its alloys form a much thicker naturally occurring oxide layer compared with stainless steel. When the oxide film is mechanically abraded (from any metal), this allows for the release of metal ions from the highly reactive and less biocompatible bulk material. This undesirable release of potentially toxic metal ions continues until the oxide layer can be regenerated [39]. In general the most toxic components (cobalt, chromium, nickel and iron) are found in and released from stainless steel [41]. The toxicity of these elements has been observed to negatively impact the vascular, reproductive, excretory, sensory and respiratory systems [39].

In association with stainless-steel-based and cobalt-based materials, contact hypersensitivity reactions have been described and were mostly attributed to chromium, cobalt, nickel, and occasionally to molybdenum [42]. In contrast, due to its excellent biocompatibility, titanium is not considered to provoke allergic reactions. However, in view of the few reports on contact dermatitis or granulomatous reactions to titanium upon its use in pacemakers or implants [43-45], the discussion about 'titanium allergy' is still ongoing.

Furthermore, stainless steel produces more imaging artefacts compared with titanium owing to its composition, which increases its magnetic susceptibility [39]. The pure titanium implants are not ferromagnetic and do not cause harm to patients in magnetic resonance imaging (MRI) units [39,40].

Finally, when comparing stainless steel with titanium it must be recognised that steel is usually electropolished (EPSS) to a smooth surface, whereas titanium in its standard form has a microrough surface. Therefore, when comparing steel with titanium there is not only a material difference but also a topographical difference. These mentioned surface differences 


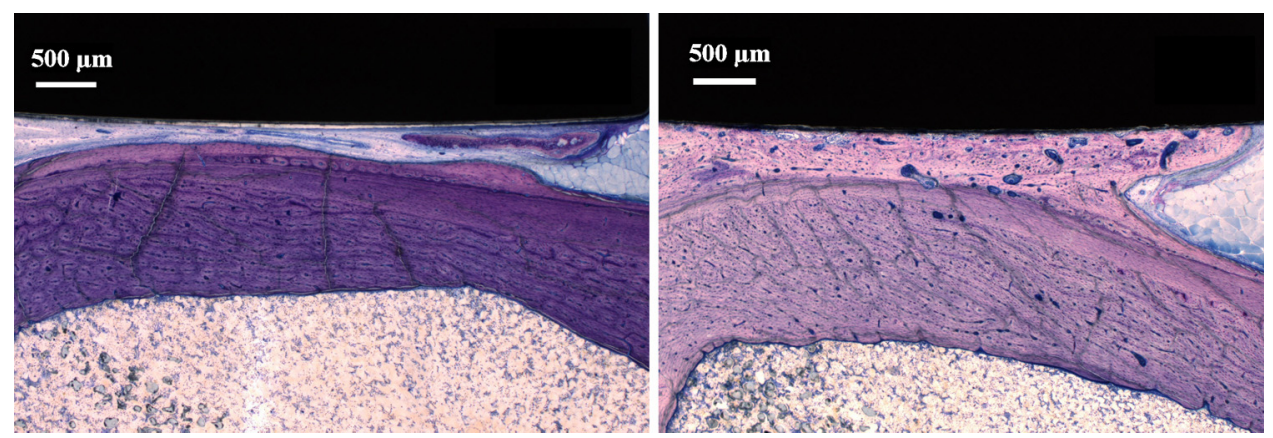

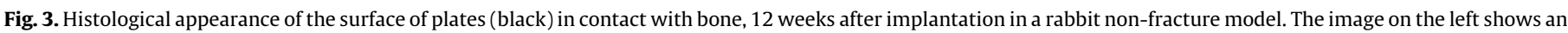

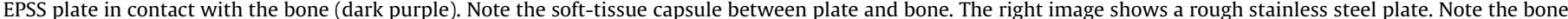

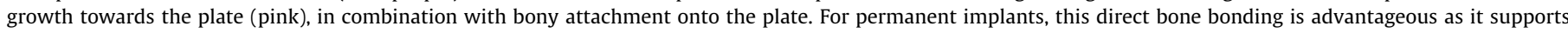
implant stability (copyright by AO Foundation, Switzerland) [12].

have not only implications for osseointegration, but also for softtissue adhesions. EPSS is void of micro discontinuities, this generally supports fibrous-osseous integration upon implantation (Fig. 3) $[12,39,46]$. The standard microrough surface of titanium supports direct osseointegration $[12,39,46]$, which is also true for rough steel (Fig. 3). This shows that EPSS and titanium have different biocompatibility characteristics.

Improved adhesion of tissue to microrough titanium over EPSS could be the reason for the reduced prevalence of capsule formation around titanium implants in comparison with EPSS implants (Fig. 4) [12,39,47]. In a rabbit model, Ungersbock et al. also found a fluid film between the EPSS implants and the adjacent tissue layer [48]. A fibrous capsule surrounding a liquid-filled void at the tissue-implant interface, creating a dead-space, without vascularisation, favours the development of infection [49,50]. The interior of the capsule is avascular and thus isolated from its surroundings [48]. This means that microorganisms are protected from outside aggressors such as macrophages and antibiotics. Earlier experimental data (in vitro and in vivo) indeed indicated that titanium is superior to EPSS regarding infection susceptibility $[17,51,52]$. However, these studies have some potential cofounders making it difficult to draw conclusions or to translate data to the clinical situation. One of the cofounders is the use of different types of plates. As already mentioned earlier, when comparing the results of PC-Fix/LCP studies to DCP studies, it must be considered that the DCP acts by compressing the plate onto the bone over a large contact area resulting in damage to the periosteal vasculature with resulting necrosis and by itself higher infection rates [8,14]. A more recent study by Hudetz et al. compared titanium and EPSS in a 'subcutaneous' mouse model. The authors stated that the metal played a minor role in susceptibility to and persistence of staphylococcal infections [76].

Although it seems that direct osseointegration as occurs with the microrough surface of titanium is positive, it also leads to excessive tissue adhesions which complicates implant removal and impairs limb function, for example with tendon adhesion after fixation of distal radius fractures [46,47,53,54]. Polishing of titanium and its alloys is currently being investigated as a potential approach for improving this outcome. Prior to clinical implementation, the effect of polishing the surface of these devices on infection rates needs to be ascertained, since polishing the surface of commonly used metals can not only alter the biocompatibility of the implant (with creation of a dead-space) as mentioned earlier but also change bacterial adhesion in vitro $[50,52,55]$.

In an experimental study, Moriarty et al. investigated infection rates of titanium, TAN and EPSS LCP implants in a non-fracture rabbit model. No statistically significant differences were found between materials, even when the microtopography was changed (polished) [49]. As we know that fracture biomechanics may influence infection susceptibility, and the previous study used a non-fracture model, further studies are required to definitively determine the role of implant material and topography on implant-related infections [2]. A suitable rabbit fracture model has recently been described. Current work at the AO Research Institute, Davos, Switzerland, focuses on testing infection susceptibility of different metals in this biomechanically loaded model (Fig. 5).

Only a few clinical studies compare titanium and EPSS. Holzach et al. showed no differences in outcome after the treatment of
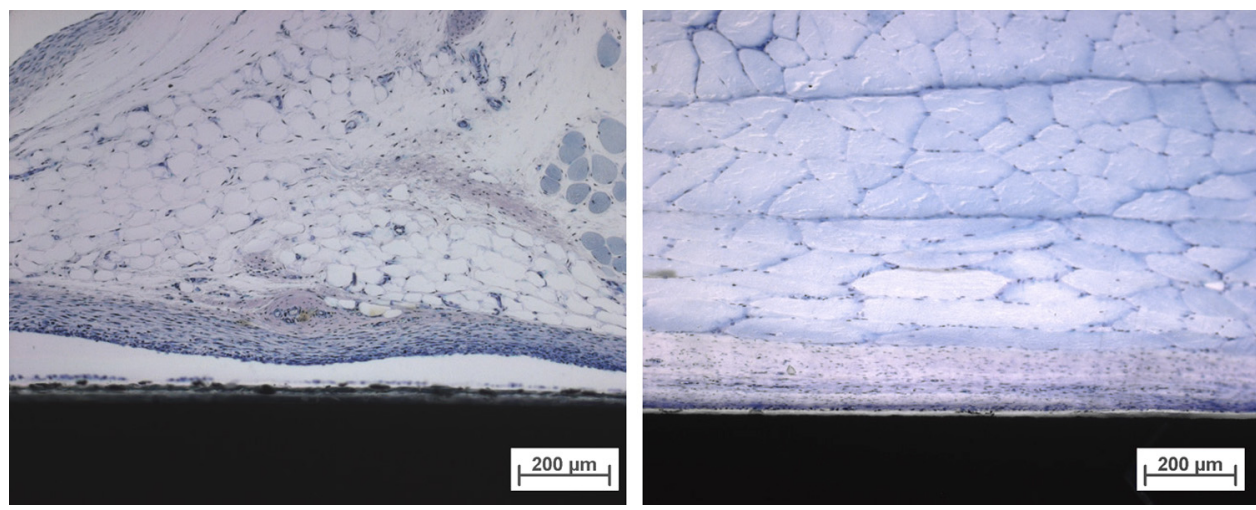

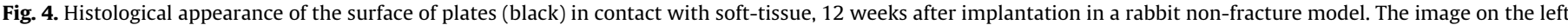

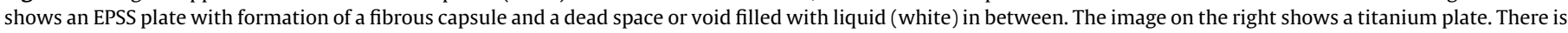

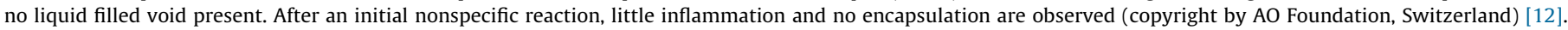

Please cite this article in press as: Metsemakers W-J, et al. Influence of implant properties and local delivery systems on the outcome in operative fracture care. Injury (2016), http://dx.doi.org/10.1016/j.injury.2016.01.019 


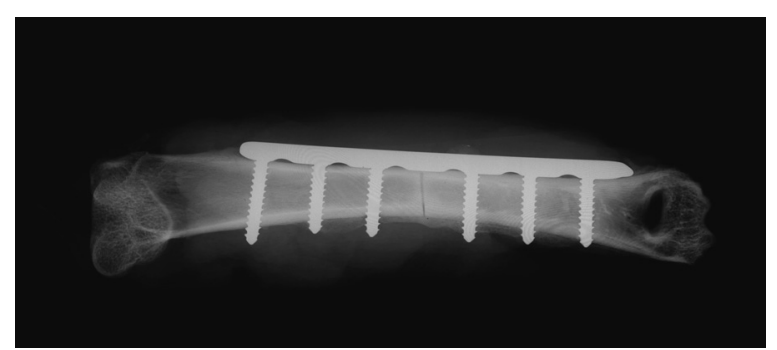

Fig. 5. Contact radiograph of a rabbit fracture model. In this model an osteosynthesis is performed using a 2.0 Locking Compression Plate (LCP) in combination with 6 locking screws. At hole 4 an osteotomy is created with a Gigli wire after which the plate is inoculated with Staphylococcus aureus. Images reproduced with kind permission of the AO Research Institute Davos, Switzerland.

256 fractures of the tibia using DCP implants. In this series, EPSS and titanium had the same good clinical outcome [56]. More recently results from the SPRINT-trial were published [36]. The investigators noted that when comparing EPSS intramedullary nails to titanium nails for the treatment of tibial shaft fractures, the EPSS nails had a higher risk of a negative event. Further evaluation of their data revealed that this was mainly due to autodynamisation in the EPSS-group. This means that during weight bearing, the EPSS locking screws fail, leading to dynamisation of the fracture. The underlying biomechanical cause should be further studied in the future. A study performed by Clauss et al. compared percutaneous EPSS Kirschner wires with titanium Kirschner wires used during toe deformity correction [57]. The conclusion of the study was that titanium Kirschner wires had lower bacterial counts and a superior clinical outcome compared to EPSS Kirschner wires. Finally, a recent randomised controlled trial comparing the stabilisation of closed femoral shaft fractures in children, showed that both titanium and EPSS elastic nails were equally effective treatment modalities, with similar rates of complications [58].

Despite the many differences between EPSS and titanium, both materials provide a relatively predictable clinical outcome and offer similar success for fulfilling the main requirements of fracture fixation [39,59].

\section{Mixing metals in fracture care}

Surgeons are hesitant to mix components made of different metal classes for fear of galvanic corrosion. However, studies have failed to show a significant potential for galvanic corrosion between titanium, stainless steel and cobalt chromium ( $\mathrm{CoCr}$ ). In an early description in 1975, Rüedi already described that the combination of titanium and stainless steel appears to be possible and without danger in human patients [60]. More recently, an in vitro study by $\mathrm{Høl}$ et al. showed that the combination of titanium and stainless steel screws and plates did not cause higher weight loss of the components or metal release than the single-material constructions, indicating comparable clinical safety [61]. Interestingly enough, in an in vitro study, Serhan et al. noted that when using spinal implants the galvanic corrosion is less pronounced in stainless steel-titanium mixed interfaces than in pure stainless steel constructs [84]. Wächter et al. performed a short-term in vivo study. A mandibular defect in sheep was bridged using a titanium plate in combination with titanium or stainless steel screws [62]. In this study the combination of dissimilar screws and plates did not cause a higher weight loss or metal release than the singlematerial constructions, indicating comparable clinical safety. In an in vivo model in sheep, Devine et al. confirmed these statements using $\mathrm{CoCr}$ guide wires in combination with stainless steel cannulated screws [63].

In a clinical setting, it has already been proven in a study by Acevedo et al. that mixing implants with different metallic compositions on the same bone, for the treatment of upperextremity fractures, does not increase the existence of corrosion or complications [64]. It has to be stated that in this study the titanium and stainless steel implants were in close proximity to each other, without actual direct contact.

We conclude that although the mixture of titanium with stainless steel is stated as 'off label use', there is no evidence from large clinical trials showing the direct relationship with a negative outcome [65].

\section{Local delivery systems in fracture care}

\section{Introduction of systemic antibiotics}

A large randomised clinical trial in the Netherlands, including 2195 patients, revealed that adequate single-dose antibiotic prophylaxis substantially reduces the incidence of implant-related infection after surgery for closed fractures [66]. Although an experimental study by Worlock et al. showed promising results, an equivalent large randomised trial has never been conducted for open fractures [67]. A Cochrane analysis, summarising different smaller studies, stated that the prophylactic administration of systemic antibiotics for open fractures was associated with an absolute risk reduction of $60 \%$ in developing infections compared with placebo [68]. Guidelines from the Surgical Infection Society support this conclusion and stated that a short course of firstgeneration cephalosporins, begun as soon as possible after the injury, significantly lowers the risk of infection in open fractures, when used in combination with prompt, fracture and wound management [69]. This is now accepted as standard of care.

\section{Local delivery of antibiotics}

Implant-related infections are typically caused by biofilm forming bacteria $[70,71]$. In contrast to infections caused by free-floating (planktonic) bacteria, these infections generally persist despite susceptibility of the causative bacteria to antimicrobials. Furthermore, host defences are unable to eradicate these microorganisms, which are protected by a highly hydrated extracellular (exopolysaccharid) matrix (Fig. 6).

Improved infection prophylaxis could be achieved by incorporating potent antimicrobials into local delivery systems that protect both the implant surface from biofilm formation, but also the surrounding tissues.

Despite the use of systemic antibiotics, open fractures still have higher infection rates compared to closed fractures, especially in

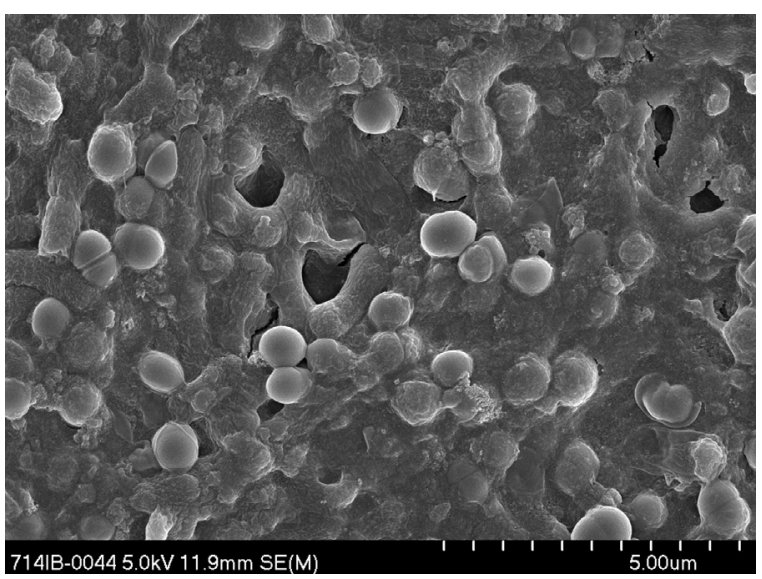

Fig. 6. Scanning electron microscope (SEM) image of in vitro biofilm formation by Staphylococcus aureus on a titanium disc. Images reproduced with kind permission of the AO Research Institute, Davos, Switzerland. 
the region of the tibia $[36,72,73]$. One of the suggested reasons is that systemic antibiotics may not reach the tissue-implant interface in high enough concentrations to eradicate bacteria due to local vascular damage. Locally delivering antibiotics is seen as an easy way to overcome this problem. A recently performed meta-analysis on the additional benefit of local antibiotic therapy in open tibia fractures showed that the rate of infection was lower for all Gustilo-Anderson grades of open tibia fractures when local antibiotics were administered as adjunctive prophylactic therapy [74]. Patients with higher grades of open fractures, for example Gustilo grade III open injuries, obtained the greatest benefit from this treatment. Local delivery systems in this study ranged from antibiotic-loaded polymethylmethacrylate (PMMA) beads to antibiotic coated tibia nails $[75,76]$. Although antibiotic-loaded PMMA beads have been shown to reduce acute and chronic infections in the most severe fracture cases, the beads require second surgery for removal, or, in case of the bead pouch technique, delay wound closure significantly. Moreover systematic review of the available literature showed that no large prospective study has thus far proven that antibiotic-loaded PMMA beads are effective in treating implant-related infections (Fig. 7) [77].

There are more reasons why different authors question the use of PMMA as local delivery system. In a study by van de Belt et al., the release profiles of six types of bone cements were investigated in vitro [78]. The authors showed that the released antibiotic fell below the detection limit after one week and that a total of only 4$17 \%$ of the incorporated antibiotic (gentamicin) was finally released. In a clinical study by Neut et al., the authors retrieved gentamicin-loaded PMMA beads after revision surgery for prosthetic joint infections [79]. Extensive culture procedures indicated the presence of bacteria on gentamicin-loaded beads in 18 of the 20 patients involved. Nineteen of 28 bacterial strains isolated were gentamicin resistant and cultures from three patients yielded highly gentamicin-resistant sub-populations. The authors stated that the use of gentamicin-loaded PMMA beads may contribute to the occurrence of re-infection with resistant variants. Concerns have therefore been raised over the

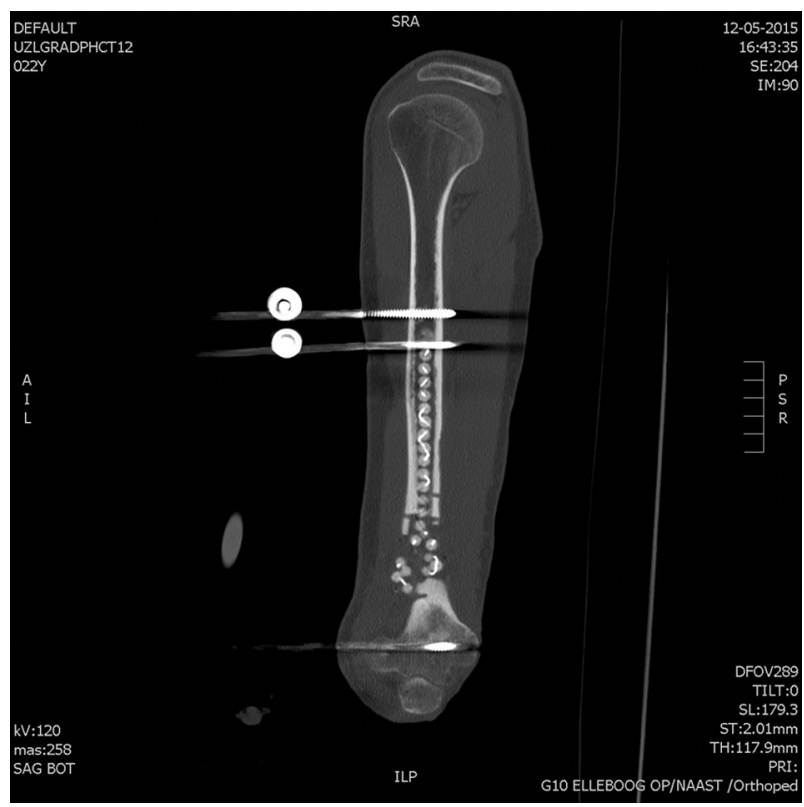

Fig. 7. Computed tomography (CT) image of gentamicin-loaded PMMA beads, used in a case of chronic implant-related infection after plate osteosynthesis of a distal humerus fracture. Note that there has been bone loss after resection of a large bone sequester. development of antibiotic resistance due to the prolonged release of antibiotics at a sub-therapeutic level from local delivery vehicles with suboptimal release profiles [80].

The application of antibiotics through an implant coating is a relatively new development [81]. Antibiotic coated intramedullary nails do not necessitate additional removal surgeries or delay wound closure, furthermore the release profiles from coatings seem superior to that of PMMA without longstanding release of antibiotics at a sub-therapeutic level [82]. These coated implants have already shown initial promising results. Lucke et al. performed an experimental study to compare systemic antibiotics with the administration of local antibiotics for the prevention of osteomyelitis [83]. The medullary cavities of rat tibiae were contaminated with $S$. aureus and titanium Kirschner wires were implanted into the medullary canals. The implants were coated with a layer of poly(D,L-lactide) (PDLLA) loaded with gentamicin. The onset of infection was prevented in $80-90 \%$ of animals treated with gentamicin-coated Kirschner wires, with and without systemic prophylaxis. Fuchs et al. published a study including 29 patients treated with a gentamicin-coated tibia nail [76]. The study population included patients with complex tibial fractures and late revision cases. No implant-related infections occurred. The only trauma related implant that has been available on the European market was the PROtect ${ }^{\circledR}$ tibia nail (DepuySynthes, Johnson/Johnson company, Inc New Jersey, USA). It is coated with a layer of poly(D,L-lactide) (PDLLA) impregnated with gentamicin.

The current antibiotics of choice for incorporation in local delivery systems are aminoglycosides (e.g. gentamicin). Concerns have been raised regarding the emergence of resistance against aminoglycosides, particularly secondary to gentamicin used in local delivery vehicles [84,85]. Recently, a study by Metsemakers et al. investigated the efficacy of a biodegradable Polymer-Lipid Encapsulation MatriX (PLEX) loaded with the antibiotic doxycycline as a local prophylactic strategy against implant-related infection [82]. While the previously mentioned PDLLA coating on the PROtect ${ }^{\circledR}$ tibia nail (DepuySynthes, Johnson/Johnson company, Inc New Jersey, USA) releases $80 \%$ of the gentamicin in $48 \mathrm{~h}$, this coating shows a burst release of $25 \%$ the first day followed by a daily sustained release of $3 \%$ up to 28 days. An advantage of using doxycycline is that its resistance amongst the most commonly encountered microorganisms causing implant-related infection, including methicillin-resistant $S$. aureus (MRSA), is still very low [86]. Furthermore, doxycycline enters host cells very efficiently and thus may target the population of intracellular bacteria, which gentamicin is less able to reach. Intracellular persistence of staphylococci in tissue surrounding implants, especially in large numbers within macrophages, is a welldescribed phenomenon $[87,88]$. This lack of clearance is likely due to impairment of the host immune response in the presence of an implant, also known as 'frustrated phagocytosis' [89]. The authors stated that the PLEX-coating loaded with doxycycline protected against implant-related infection caused by doxycycline-sensitive, methicillin-sensitive $S$. aureus in a non-fracture rabbit model (Fig. 8). Even when rabbits were challenged with a doxycycline-resistant, methicillin-resistant $S$. aureus (MRSA) strain, the PLEX coating significantly reduced the proportion of culture-positive samples.

Such antibiotic coated implants seem a potential option for the prevention and treatment of infection in trauma patients with open fractures and in septic revision cases [90,91]. In the future, the development of biodegradable products like thermo-responsive hydrogels, loaded with antimicrobials, would give the musculoskeletal trauma surgeon a choice during surgery regarding the implant or surface (e.g. bone, soft-tissue, plate or intramedullary nail) he would like to protect by local application of this patient specific 'gel-coating' [92]. 


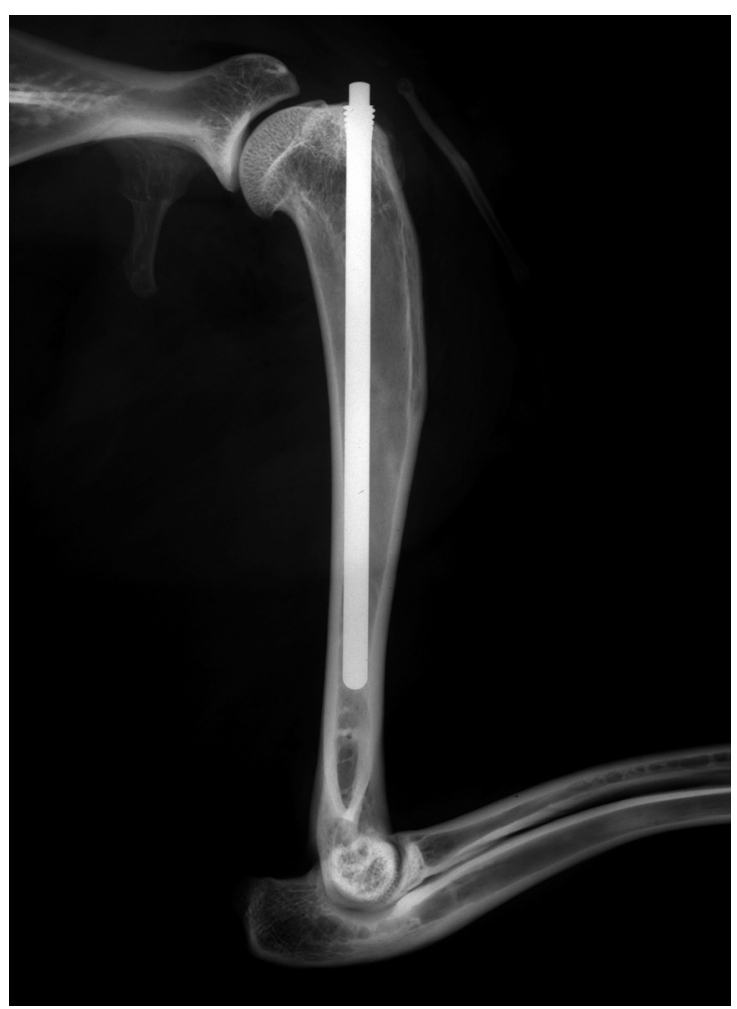

Fig. 8. Contact radiograph of a PLEX-doxycycline coated implant in a rabbit nonfracture model. Images reproduced with kind permission of the AO Research Institute, Davos, Switzerland.[82].

\section{Local delivery of antimicrobial peptides}

The rise in antibiotic resistant bacteria is driving researchers to new treatment options. Antimicrobial peptides (AMP's) have been recognised as promising candidates for the new generation of antimicrobial surfaces $[93,94]$. AMP's are evolutionarily conserved molecules involved in the defence mechanisms of a wide range of organisms [93]. Produced in bacteria, insects, plants and vertebrates, different AMP's protect against a broad array of infectious agents [93]. They have been the focus of great interest in recent years owing to a low propensity for developing bacterial resistance, broad-spectrum activity, high efficacy at very low concentrations, target specificity, and synergistic action with classical antibiotics [94]. Animal osteomyelitis models showed that certain AMP's reduced bone infection caused by antibiotic resistant and non-resistant strains of bacteria [95,96]. Currently, cost and toxicity concerns have rendered their use restricted [97]. They often display unspecific toxicity to cells, derived from their interactions with any bilayer membrane; thus their devastating power requires modulation. In the future, AMP's require covalent modifications and/or novel formulations to become less toxic, more bioavailable and useful in the biomedical field [98].

\section{Local delivery of bone morphogenetic proteins}

Bone healing is also a potential target for local delivery systems in fracture care. A current topic of interest, not only in acute fracture care but also for the treatment of nonunion, is the use of bone morphogenetic proteins (BMP's). They are members of the transforming growth factor (TGF)-beta superfamily and are known to be very potent osteoinductive growth factors [99].

Animal studies have shown the potential of BMP-2 in acute fracture care [100,101]. A few clinical trials have been conducted to evaluate the use of BMP-2 in the management of open tibial fractures treated with intramedullary fixation. The results were contradictory. The BESTT-trial showed that local application of BMP-2, using an absorbable collagen sponge, was significantly superior to the standard of care in reducing the frequency of secondary interventions, accelerating fracture healing, and reducing the infection rate [102]. The BESTT-ALL study-group again had positive results and noted that BMP-2 in combination with allograft is safe and as effective as traditional autogenous bonegrafting for the treatment of tibial fractures associated with extensive traumatic diaphyseal bone loss [103]. But a more recent trial by Aro et al. could not repeat these findings [104]. The author stated that BMP-2 did not accelerate fracture healing in open tibial fractures. Moreover, there was a trend towards higher infection rates in the BMP-2 group. Probably methodological differences lie at the basis of these different outcomes [105].

There are some potential hazards to the local application using carriers, like collagen sponges, impregnated with BMP's in open or closed fracture sites. Not only infection, but also ectopic bone formation in non-target tissue like blood vessels and nerves could become a problem [106]. Schmidmaier et al. stated that the use of BMP-2 coated implants could overcome these clinical problems [107]. In a rat model, the authors showed that the use of these implants is feasible and accelerates fracture healing. More recently, Strobel et al. published an in vitro study were they investigated the sequential release of an antibiotic and growth factors from coated implants [108]. The authors stated that the local application of antibiotics in combination with timely controlled growth factor delivery might be beneficial for the prevention of infections and stimulate bone healing at the same time [108].

The treatment of nonunions often requires the use of additional grafting material, in this setting autologous bone remains the gold standard [109]. However, the considerable donor site morbidity associated with this procedure, the reduced availability of autologous bone graft and the reduced biological activity of MSC in autograft as the donor ages, represent relative limiting factors for its use [109,110]. In this setting further research on fracture healing focused on growth factors, like BMP's. As described in the Diamond-concept by Giannoudis et al., the application of these exogenous growth factors can play an important role in the treatment of nonunions [111]. The registration of BMP-7, also known as human osteogenic protein-1 (OP-1), for tibia nonunions was largely based upon one of the first randomised clinical trials on BMP-7, published in 2001 by Friedlaender et al. [112]. Following this study, the role of BMP-7 in stimulating bone healing has been evaluated extensively and its efficacy has been assessed in the treatment of different long bone fracture nonunions with encouraging results [113-115]. Giannoudis et al. published a retrospective analysis of 45 patients treated with both BMP-7 and autograft [116]. These patients underwent a mean of 2 prior operations (range 1-7), and the nonunions were located in long bones ( 7 humerus, 19 femur and 19 tibia). All nonunions healed after a median of 5 months.

Future prospective randomised trials should evaluate the definitive place of BMP's in prevention and treatment of compromised fracture healing.

\section{Conclusions and future perspectives}

Two of the major problems in musculoskeletal trauma surgery today are compromised fracture healing and implant-related infection $[1,2]$. As already published by previous authors, they are difficult to treat and have a high socio-economic impact [3-5]. All strategies that help to reduce these complications, will not only 
lead to a faster resumption of activities, it also helps to reduce the financial burden of overall healthcare costs.

Important is that the surgical approach, the fixation device used and further, the design of the chosen fracture fixation device and its application can influence the susceptibility to these musculoskeletal complications.

Both materials that are most often used in fracture care today, EPSS and titanium, provide a relatively predictable clinical outcome and offer similar success for fulfilling the main requirements of fracture fixation [39,59].

With respect to implant-related infections, research focuses on biofilm forming bacteria. Most antimicrobial agents have a limited efficacy against biofilm infections; therefore novel preventive and therapeutic options are needed [117]. Local delivery systems, like implant coatings, could be an asset in this field. Furthermore, the increased prevalence of antibiotic-resistant bacteria, particularly MRSA, has become a significant global healthcare issue $[118,119]$. For this reason future studies will focus on other non-antibiotic substances such as AMP's and silver [94,120].

Finally, measures that prevent complications are currently of more interest as the cost burden on total health care expenditures due to these negative events, will only increase [7].

\section{Conflict of interest}

All authors declare no conflict of interest with respect to the preparation and writing of this article.

\section{Acknowledgement}

No benefits in any form have been received or will be received from a commercial party related directly or indirectly to the subject of this article.

\section{References}

[1] Bishop JA, Palanca AA, Bellino MJ, Lowenberg DW. Assessment of compromised fracture healing. J Am Acad Orthop Surg 2012;20:273-82.

[2] Schmidt AH, Swiontkowski MF. Pathophysiology of infections after internal fixation of fractures. J Am Acad Orthop Surg 2000;8:285-91.

[3] Darouiche RO. Treatment of infections associated with surgical implants. N Engl J Med 2004;350:1422-9.

[4] Tay WH, de Steiger R, Richardson M, Gruen R, Balogh ZJ. Health outcomes of delayed union and nonunion of femoral and tibial shaft fractures. Injury 2014;45:1653-8

[5] Hak DJ, Fitzpatrick D, Bishop JA, Marsh JL, Tilp S, Schnettler R, et al. Delayed union and nonunions: epidemiology, clinical issues, and financial aspects. Injury 2014;45(Suppl. 2):S3-7.

[6] Saddawi-Konefka D, Kim HM, Chung KC. A systematic review of outcomes and complications of reconstruction and amputation for type IIIB and IIIC fractures of the tibia. Plast Reconstruct Surg 2008;122:1796-805.

[7] Chung KC, Saddawi-Konefka D, Haase SC, Kaul G. A cost-utility analysis of amputation versus salvage for Gustilo type IIIB and IIIC open tibial fractures. Plast Reconstruct Surg 2009;124:1965-73.

[8] Perren SM. Evolution of the internal fixation of long bone fractures. The scientific basis of biological internal fixation: choosing a new balance between stability and biology. J Bone Joint Surg [Br] 2002;84:1093-110.

[9] Horn J, Schlegel U, Krettek C, Ito K. Infection resistance of unreamed solid, hollow slotted and cannulated intramedullary nails: an in-vivo experimental comparison. J Orthop Res: Off Pub Orthop Res Soc 2005;23:810-5.

[10] Schlegel U, Perren SM. Surgical aspects of infection involving osteosynthesis implants: implant design and resistance to local infection. Injury 2006;37(Suppl. 2):S67-73.

[11] Arens S, Hansis M, Schlegel U, Eijer H, Printzen G, Ziegler WJ, et al. Infection after open reduction and internal fixation with dynamic compression plates clinical and experimental data. Injury 1996;27(Suppl. 3):SC27-33.

[12] Ruedi TP, Buckley RE, Moran CG, Ito K, Perren SM, Richards RG, et al. AO principles of fracture management - vol. 1 - Principles - second expanded edition. 2nd ed. Thieme; 2007.

[13] Moriarty TF, Schlegel U, Perren S, Richards RG. Infection in fracture fixation: can we influence infection rates through implant design. J Mater Sci Mater Med 2010;21:1031-5.

[14] Eijer H, Hauke C, Arens S, Printzen G, Schlegel U, Perren SM. PC-Fix and local infection resistance - influence of implant design on postoperative infection development, clinical and experimental results. Injury 2001;32(Suppl. 2):B38-43.

[15] Wagner M. General principles for the clinical use of the LCP. Injury 2003;34(Suppl. 2):B31-42.

[16] Kuntscher GB. The Kuntscher method of intramedullary fixation. J Bone Joint Surg [Am] 1958;40-A:17-26.

[17] Melcher GA, Hauke C, Metzdorf A, Perren SM, Printzen G, Schlegel U, et al. Infection after intramedullary nailing: an experimental investigation on rabbits. Injury 1996;27(Suppl. 3):SC23-6.

[18] Melcher GA, Claudi B, Schlegel U, Perren SM, Printzen G, Munzinger J. Influence of type of medullary nail on the development of local infection. An experimental study of solid and slotted nails in rabbits. J Bone Joint Surg [Br] 1994;76:955-9.

[19] Riemer BL, Sagiv S, Butterfield SL, Burke 3rd CJ. Tibial diaphyseal nonunions after external fixation treated with nonreamed solid core nails. Orthopedics 1996;19:109-16.

[20] Bhandari M, Zlowodzki M, Tornetta 3rd P, Schmidt A, Templeman DC. Intramedullary nailing following external fixation in femoral and tibial shaft fractures. J Orthop Trauma 2005;19:140-4.

[21] Pfeifer R, Sellei R, Pape HC. The biology of intramedullary reaming. Injury 2010;41(Suppl. 2):S4-8.

[22] Wenisch S, Trinkaus K, Hild A, Hose D, Herde K, Heiss C, et al. Human reaming debris: a source of multipotent stem cells. Bone 2005:36:74-83.

[23] Rommens PM, Kuechle R, Bord T, Lewens T, Engelmann R, Blum J. Humeral nailing revisited. Injury 2008;39:1319-28.

[24] Klein MP, Rahn BA, Frigg R, Kessler S, Perren SM. Reaming versus nonreaming in medullary nailing: interference with cortical circulation of the canine tibia. Arch Orthop Trauma Surg 1990;109:314-6.

[25] Muller C, McIff T, Rahn BA, Pfister U, Perren SM, Weller S. Influence of the compression force on the intramedullary pressure development in reaming of the femoral medullary cavity. Injury 1993;24(Suppl. 3):S36-9.

[26] Baumgart F, Kohler G, Ochsner PE. The physics of heat generation during reaming of the medullary cavity. Injury 1998;29(Suppl. 2):B11-25.

[27] Harwood PJ, Giannoudis PV, van Griensven M, Krettek C, Pape HC. Alterations in the systemic inflammatory response after early total care and damage control procedures for femoral shaft fracture in severely injured patients. J Trauma 2005:58:446-52. discussion 52-4.

[28] Pape HC, Rixen D, Morley J, Husebye EE, Mueller M, Dumont C, et al. Impact of the method of initial stabilization for femoral shaft fractures in patients with multiple injuries at risk for complications (borderline patients). Ann Surg 2007:246:491-9. discussion 9-501.

[29] Canadian Orthopaedic Trauma Society. Reamed versus unreamed intramedullary nailing of the femur: comparison of the rate of ARDS in multiple injured patients. J Orthop Trauma 2006;20:384-7.

[30] Ricci WM, Gallagher B, Haidukewych GJ. Intramedullary nailing of femoral shaft fractures: current concepts. J Am Acad Orthop Surg 2009;17: 296-305.

[31] Giannoudis PV, Furlong AJ, Macdonald DA, Smith RM. Reamed against unreamed nailing of the femoral diaphysis: a retrospective study of healing time. Injury 1997;28:15-8.

[32] Reynders PA, Broos PL. Healing of closed femoral shaft fractures treated with the AO unreamed femoral nail. A comparative study with the AO reamed femoral nail. Injury 2000;31:367-71

[33] el Moumni M, Leenhouts PA, ten Duis HJ, Wendt KW. The incidence of nonunion following unreamed intramedullary nailing of femoral shaft fractures. Injury 2009;40:205-8.

[34] Shepherd LE, Shean CJ, Gelalis ID, Lee J, Carter VS. Prospective randomized study of reamed versus unreamed femoral intramedullary nailing: an assessment of procedures. J Orthop Trauma 2001;15:28-32. discussion -3.

[35] Metsemakers WJ, Roels N, Belmans A, Reynders P, Nijs S. Risk factors for nonunion after intramedullary nailing of femoral shaft fractures: remaining controversies. Injury 2015;46:1601-7.

[36] Schemitsch EH, Bhandari M, Guyatt G, Sanders DW, Swiontkowski M, Tornetta $\mathrm{P}$, et al. Prognostic factors for predicting outcomes after intramedullary nailing of the tibia. J Bone Joint Surg [Am] 2012:94:1786-93.

[37] Metsemakers WJ, Handojo K, Reynders P, Sermon A, Vanderschot P, Nijs S Individual risk factors for deep infection and compromised fracture healing after intramedullary nailing of tibial shaft fractures: a single centre experience of 480 patients. Injury 2015;46:740-5.

[38] Schemitsch EH, Kowalski MJ, Swiontkowski MF, Senft D. Cortical bone blood flow in reamed and unreamed locked intramedullary nailing: a fractured tibia model in sheep. J Orthop Trauma 1994:8:373-82.

[39] Hayes JS, Richards RG. The use of titanium and stainless steel in fracture fixation. Expert Rev Med Dev 2010;7:843-53.

[40] Pohler OE. Unalloyed titanium for implants in bone surgery. Injury 2000;31(Suppl. 4):7-13.

[41] Krischak GD, Gebhard F, Mohr W, Krivan V, Ignatius A, Beck A, et al. Difference in metallic wear distribution released from commercially pure titanium compared with stainless steel plates. Arch Orthop Trauma Surg 2004;124: 104-13.

[42] Thomas P, Bandl WD, Maier S, Summer B, Przybilla B. Hypersensitivity to titanium osteosynthesis with impaired fracture healing, eczema, and T-cell hyperresponsiveness in vitro: case report and review of the literature. Contact Dermat 2006;55:199-202.

[43] Lalor PA, Revell PA, Gray AB, Wright S, Railton GT, Freeman MA. Sensitivity to titanium. A cause of implant failure? J Bone Joint Surg [Br] 1991;73:25-8. 
[44] Xu ZQ, Xu C, Zhan JD, Yu XL. Allergic to titanium plate fixation implants after operation of tibial plateau fracture: a case report. Zhongguo Gu Shang 2014;27:1047-9.

[45] Viraben R, Boulinguez S, Alba C. Granulomatous dermatitis after implantation of a titanium-containing pacemaker. Contact Dermat 1995;33:437.

[46] Hayes JS, Vos DI, Hahn J, Pearce SG, Richards RG. An in vivo evaluation of surface polishing of TAN intermedullary nails for ease of removal. Eur Cells Mater 2009;18:15-26.

[47] Hayes JS, Richards RG. Surfaces to control tissue adhesion for osteosynthesis with metal implants: in vitro and in vivo studies to bring solutions to the patient. Expert Rev Med Devices 2010;7:131-42.

[48] Ungersbock A, Pohler O, Perren SM. Evaluation of the soft tissue interface at titanium implants with different surface treatments: experimental study on rabbits. Bio-med Mater Eng 1994;4:317-25.

[49] Moriarty TF, Debefve L, Boure L, Campoccia D, Schlegel U, Richards RG. Influence of material and microtopography on the development of local infection in vivo: experimental investigation in rabbits. Int $\mathrm{J}$ Artif Org 2009;32:663-70.

[50] Harris LG, Richards RG. Staphylococci and implant surfaces: a review. Injury 2006:37(Suppl. 2):S3-14.

[51] Arens S, Schlegel U, Printzen G, Ziegler WJ, Perren SM, Hansis M. Influence of materials for fixation implants on local infection. An experimental study of steel versus titanium DCP in rabbits. J Bone Joint Surg [Br] 1996;78:647-51.

[52] Harris LG, Meredith DO, Eschbach L, Richards RG. Staphylococcus aureus adhesion to standard micro-rough and electropolished implant materials. J Mater Sci Mater Med 2007; 18:1151-6.

[53] Sinicropi SM, Su BW, Raia FJ, Parisien M, Strauch RJ, Rosenwasser MP. The effects of implant composition on extensor tenosynovitis in a canine distal radius fracture model. J Hand Surg 2005;30:300-7.

[54] Hayes JS, Seidenglanz U, Pearce AI, Pearce SG, Archer CW, Richards RG. Surface polishing positively influences ease of plate and screw removal. Eur Cells Mater 2010;19:117-26.

[55] Harris LG, Richards RG. Staphylococcus aureus adhesion to different treated titanium surfaces. J Mater Sci Mater Med 2004;15:311-4.

[56] Holzach P, Matter P. The comparison of steel and titanium dynamic compression plates used for internal fixation of 256 fractures of the tibia. Injury 1978;10:120-3.

[57] Clauss M, Graf S, Gersbach S, Hintermann B, Ilchmann T, Knupp M. Material and biofilm load of $\mathrm{K}$ wires in toe surgery: titanium versus stainless steel. Clin Orthop Relat Res 2013;471:2312-7.

[58] Goyal N, Aggarwal AN, Mishra P, Jain A. Randomized controlled trial comparing stabilization of fresh close femoral shaft fractures in children with titanium elastic nail system versus stainless steel elastic nail system. Acta Orthop Belg 2014;80:69-75.

[59] Weckbach S, Losacco JT, Hahnhaussen J, Gebhard F, Stahel PF. Challenging the dogma on inferiority of stainless steel implants for fracture fixation. An end of the controversy? Unfallchirurg 2012;115:75-9.

[60] Rüedi T. Titanium and steel and their combinations in bone surgery. Langenbecks Arch Chir 1975;39:5-8.

[61] Hol PJ, Molster A, Gjerdet NR. Should the galvanic combination of titanium and stainless steel surgical implants be avoided. Injury 2008;39:161-9.

[62] Wachter R, Stoll P. Can steel screws be combined with titanium plates? Hard polishing technique and SEM in animal experiments. Deuts Z Mund- KieferGesichts-Chir 1991:15:275-84.

[63] Devine DM, Leitner M, Perren SM, Boure LP, Pearce SG. Tissue reaction to implants of different metals: a study using guide wires in cannulated screws. Eur Cells Mater 2009;18:40-8.

[64] Acevedo D, Loy BN, Lee B, Omid R, Itamura J. Mixing implants of differing metallic composition in the treatment of upper-extremity fractures. Orthopedics 2013;36:e1175-79.

[65] Disegi J. Implant materials. Wrought 18\% chromium-14\% nickel-2.5\% molybdenum stainless steel. 3rd ed. USA: Synthes; 2009.

[66] Boxma H, Broekhuizen T, Patka P, Oosting H. Randomised controlled trial of single-dose antibiotic prophylaxis in surgical treatment of closed fractures: the Dutch Trauma Trial. Lancet 1996;347:1133-7.

[67] Worlock P, Slack R, Harvey L, Mawhinney R. The prevention of infection in open fractures. An experimental study of the effect of antibiotic therapy. Bone Joint Surg [Am] 1988;70:1341-7.

[68] Gosselin RA, Roberts I, Gillespie WJ. Antibiotics for preventing infection in open limb fractures. Cochr Database Syst Rev 2004;CD003764

[69] Hauser CJ, Adams Jr CA, Eachempati SR, Council of the Surgical Infection Society. Surgical Infection Society guideline: prophylactic antibiotic use in open fractures: an evidence-based guideline. Surg Infect 2006;7:379-405.

[70] Gristina A. Biomaterial-centered infection: microbial adhesion versus tissue integration. 1987. Clin Orthop Relat Res 2004:4-12.

[71] Trampuz A, Zimmerli W. Diagnosis and treatment of infections associated with fracture-fixation devices. Injury 2006;37(Suppl. 2):S59-66.

[72] Papakostidis C, Kanakaris NK, Pretel J, Faour O, Morell DJ, Giannoudis PV. Prevalence of complications of open tibial shaft fractures stratified as per the Gustilo-Anderson classification. Injury 2011;42:1408-15

[73] Gaebler C, Berger U, Schandelmaier P, Greitbauer M, Schauwecker HH Applegate B, et al. Rates and odds ratios for complications in closed and open tibial fractures treated with unreamed small diameter tibial nails: a multicenter analysis of 467 cases. J Orthop Trauma 2001;15:415-23.

[74] Craig J, Fuchs T, Jenks M, Fleetwood K, Franz D, Iff J, et al. Systematic review and meta-analysis of the additional benefit of local prophylactic antibiotic therapy for infection rates in open tibia fractures treated with intramedullary nailing. Int Orthop 2014:38:1025-30.

[75] Ostermann PA, Seligson D, Henry SL. Local antibiotic therapy for severe open fractures. A review of 1085 consecutive cases. J Bone Joint Surg $[\mathrm{Br}]$ 1995;77:93-7.

[76] Fuchs T, Stange R, Schmidmaier G, Raschke MJ. The use of gentamicin-coated nails in the tibia: preliminary results of a prospective study. Arch Orthop Trauma Surg 2011;131:1419-25.

[77] Barth RE, Vogely HC, Hoepelman AI, Peters EJ. 'To bead or not to bead?' Treatment of osteomyelitis and prosthetic joint-associated infections with gentamicin bead chains. Int J Antimicrob Agents 2011;38:371-5.

[78] van de Belt H, Neut D, Uges DR, Schenk W, van Horn JR, van der Mei HC, et al. Surface roughness, porosity and wettability of gentamicin-loaded bone cements and their antibiotic release. Biomaterials 2000;21:1981-7.

[79] Neut D, van de Belt H, Stokroos I, van Horn JR, van der Mei HC, Busscher HJ. Biomaterial-associated infection of gentamicin-loaded PMMA beads in orthopaedic revision surgery. J Antimicrob Chemother 2001;47:885-91.

[80] von Eiff C, Lindner N, Proctor RA, Winkelmann W, Peters G. Development of gentamicin-resistant Small Colony Variants of S. aureus after implantation of gentamicin chains in osteomyelitis as a possible cause of recurrence. Z Orthop Ihre Grenzgeb 1998;136:268-71.

[81] Zoubos AB, Galanakos SP, Soucacos PN. Orthopedics and biofilm - what do we know? A review. Med Sci Monit: Int Med J Exp Clin Res 2012:18:RA89-96.

[82] Metsemakers WJ, Emanuel N, Cohen O, Reichart M, Potapova I, Schmid T, et al. A doxycycline-loaded polymer-lipid encapsulation matrix coating for the prevention of implant-related osteomyelitis due to doxycycline-resistant methicillin-resistant Staphylococcus aureus. J Control Release: Off J Control Release Soc 2015;209:47-56.

[83] Lucke M, Wildemann B, Sadoni S, Surke C, Schiller R, Stemberger A, et al. Systemic versus local application of gentamicin in prophylaxis of implantrelated osteomyelitis in a rat model. Bone 2005;36:770-8.

[84] Anagnostakos K, Hitzler P, Pape D, Kohn D, Kelm J. Persistence of bacterial growth on antibiotic-loaded beads: is it actually a problem. Acta Orthop 2008;79:302-7.

[85] Thomes B, Murray P, Bouchier-Hayes D. Development of resistant strains of Staphylococcus epidermidis on gentamicin-loaded bone cement in vivo. J Bone Joint Surg [Br] 2002;84:758-60.

[86] Jones RN, Stilwell MG, Wilson ML, Mendes RE. Contemporary tetracycline susceptibility testing: doxycycline MIC methods and interpretive criteria (CLSI and EUCAST) performance when testing Gram-positive pathogens. Diagn Microbiol Infect Dis 2013;76:69-72.

[87] Boelens JJ, Dankert J, Murk JL, Weening JJ, van der Poll T, Dingemans KP, et al. Biomaterial-associated persistence of Staphylococcus epidermidis in pericatheter macrophages. J Infect Dis 2000;181:1337-49.

[88] Riool M, de Boer L, Jaspers V, van der Loos CM, van Wamel WJ, Wu G, et al. Staphylococcus epidermidis originating from titanium implants infects surrounding tissue and immune cells. Acta Biomater 2014;10:5202-12.

[89] Zimmerli W, Waldvogel FA, Vaudaux P, Nydegger UE. Pathogenesis of foreign body infection: description and characteristics of an animal model. J Infect Dis $1982 ; 146: 487-97$

[90] Raschke M, Vordemvenne T, Fuchs T. Limb salvage or amputation? The use of a gentamicin coated nail in a severe, grade IIIc tibia fracture. Eur J Trauma Emerg Surg 2010;36:605-8

[91] Schmidmaier G, Lucke M, Wildemann B, Haas NP, Raschke M. Prophylaxis and treatment of implant-related infections by antibiotic-coated implants: a review. Injury 2006;37(Suppl. 2):S105-12.

[92] ter Boo GJ, Grijpma DW, Moriarty TF, Richards RG, Eglin D. Antimicrobial delivery systems for local infection prophylaxis in orthopedic- and trauma surgery. Biomaterials 2015;52:113-25.

[93] Guani-Guerra E, Santos-Mendoza T, Lugo-Reyes SO, Teran LM. Antimicrobial peptides: general overview and clinical implications in human health and disease. Clin Immunol 2010;135:1-11.

[94] Alves D, Olivia Pereira M. Mini-review: antimicrobial peptides and enzymes as promising candidates to functionalize biomaterial surfaces. Biofouling 2014;30:483-99.

[95] Faber C, Stallmann HP, Lyaruu DM, Joosten U, von Eiff C, van Nieuw Amerongen A, et al. Comparable efficacies of the antimicrobial peptide human lactoferrin 1-11 and gentamicin in a chronic methicillin-resistant Staphylococcus aureus osteomyelitis model. Antimicrob Agents Chemother 2005;49: 2438-44

[96] Stallmann HP, Faber C, Bronckers AL, Nieuw Amerongen AV, Wuisman PI. Osteomyelitis prevention in rabbits using antimicrobial peptide hLF1-11- or gentamicin-containing calcium phosphate cement. J Antimicrob Chemother 2004;54:472-6

[97] McCloskey AP, Gilmore BF, Laverty G. Evolution of antimicrobial peptides to self-assembled peptides for biomaterial applications. Pathogens 2014:3: $791-821$.

[98] Carmona-Ribeiro AM, de Melo Carrasco LD. Novel formulations for antimicrobial peptides. Int J Mol Sci 2014;15:18040-83.

[99] Wozney JM, Rosen V, Celeste AJ, Mitsock LM, Whitters MJ, Kriz RW, et al. Novel regulators of bone formation: molecular clones and activities. Science $1988 ; 242: 1528-34$

[100] Edwards 3rd RB, Seeherman HJ, Bogdanske JJ, Devitt J, Vanderby Jr R, Markel MD. Percutaneous injection of recombinant human bone morphogenetic protein-2 in a calcium phosphate paste accelerates healing of a canine tibial osteotomy. J Bone Joint Surg [Am] 2004;86-A:1425-38. 
G Model

JINJ-6578; No. of Pages 10

10

W.-J. Metsemakers et al./Injury, Int. J. Care Injured $x x x$ (2016) $x x x-x x x$

[101] Seeherman H, Li R, Bouxsein M, Kim H, Li XJ, Smith-Adaline EA, et al. rhBMP$2 /$ calcium phosphate matrix accelerates osteotomy-site healing in a nonhuman primate model at multiple treatment times and concentrations. J Bone Joint Surg [Am] 2006;88:144-60.

[102] Govender S, Csimma C, Genant HK, Valentin-Opran A, Amit Y, Arbel R, et al. Recombinant human bone morphogenetic protein-2 for treatment of open tibial fractures: a prospective, controlled, randomized study of four hundred and fifty patients. J Bone Joint Surg [Am] 2002;84-A:2123-34.

[103] Jones AL, Bucholz RW, Bose MJ, Mirza SK, Lyon TR, Webb LX, et al. Recombinant human BMP-2 and allograft compared with autogenous bone graft for reconstruction of diaphyseal tibial fractures with cortical defects. A randomized, controlled trial. J Bone Joint Surg [Am] 2006;88:1431-41.

[104] fro HT, Govender S, Patel AD, Hernigou P, Perera de Gregorio A, Popescu GI, et al. Recombinant human bone morphogenetic protein-2: a randomized trial in open tibial fractures treated with reamed nail fixation. J Bone Joint Surg [Am] 2011;93:801-8.

[105] Bhattacharyya T. Commentary on an article by Hannu T. Pro, MD, PhD, et al.: Recombinant human bone morphogenetic protein-2: a randomized trial in open tibial fractures treated with reamed nail fixation. J Bone Joint Surg [Am] 2011;93:e50.

[106] Carnage EJ, Hurwitz EL, Weiner BK. A critical review of recombinant human bone morphogenetic protein-2 trials in spinal surgery: emerging safety concerns and lessons learned. Spine J: Off J North Am Spine Soc 2011;11:471-91.

[107] Schmidmaier G, Wildemann B, Come F, Kandziora F, Haas NP, Raschke M. Bone morphogenetic protein-2 coating of titanium implants increases biomechanical strength and accelerates bone remodeling in fracture treatment: a biomechanical and histological study in rats. Bone 2002;30:816-22.

[108] Strobel C, Bormann N, Kadow-Romacker A, Schmidmaier G, Wildemann B. Sequential release kinetics of two (gentamicin and BMP-2) or three (yentamicin, IGF-I and BMP-2) substances from a one-component polymeric coating on implants. J Control Release: Off J Control Release Soc 2011;156:37-45.

[109] Blokhuis TJ, Calori GM, Schmidmaier G. Autograft versus AMPs for the treatmont of non-unions: what is the evidence? Injury 2013;44(Suppl. 1):S40-2.
[110] Caplan AI. Why are MSEs therapeutic? New data: new insight. J Pathol 2009;217:318-24.

[111] Giannoudis PV, Einhorn TA, Marsh D. Fracture healing: the diamond concept. Injury 2007;38(Suppl. 4):S3-6.

[112] Friedlaender GE, Perry CR, Cole JD, Cook SD, Cierny G, Muschler GF, et al. Osteogenic protein-1 (bone morphogenetic protein-7) in the treatment of tibial nonunions. J Bone Joint Surg [Am] 2001;83-A(Suppl. 1): S151-8.

[113] Zimmermann G, Wagner C, Schmeckenbecher K, Wentzensen A, Moghaddam A. Treatment of tibial shaft non-unions: bone morphogenetic proteins versus autologous bone graft. Injury 2009;40(Suppl. 3):S50-3.

[114] Calori GM, Tagliabue L, Gala L, d'Imporzano M, Peretti G, Albisetti W. Application of rhBMP-7 and platelet-rich plasma in the treatment of long bone non-unions: a prospective randomised clinical study on 120 patients. Injury 2008;39:1391-402.

[115] Kanakaris NK, Calori GM, Verdonk R, Burssens P, De Blase P, Capanna R, et al. Application of BMP-7 to tibial non-unions: a 3-year multicenter experience. Injury 2008;39(Suppl. 2):S83-90.

[116] Giannoudis PV, Kanakaris NK, Dimitriou R, Gill I, Kolimarala V, Montgomery RJ. The synergistic effect of autograft and BMP-7 in the treatment of atrophic nonunions. Chin Orthop Relat Res 2009;467:3239-48.

[117] Zimmerli W. Clinical presentation and treatment of orthopaedic implantassociated infection. J Int Med 2014;276:111-9.

[118] Oliveira DC, Tomasz A, de Lencastre H. Secrets of success of a human pathogen: molecular evolution of pandemic clones of meticillin-resistant Staphylococcus aureus. Lancet Infect Dis 2002;2:180-9.

[119] Helbig L, Simank HG, Lorenz H, Putz C, Wolf l C, Sudra AJ, et al. Establishment of a new methicillin resistant Staphylococcus aureus animal model of osteomyelites. Int Orthop 2014;38:891-7.

[120] Gosheger G, Harden J, Ahrens H, Streitburger A, Burger H, Erren M, et al. Silver-coated megaendoprostheses in a rabbit model - an analysis of the infection rate and toxicological side effects. Biomaterials 2004;25: 5547-56.

Please cite this article in press as: Metsemakers W-J, et al. Influence of implant properties and local delivery systems on the outcome in operative fracture care. Injury (2016), http://dx.doi.org/10.1016/j.injury.2016.01.019 